\title{
Comunicação
}

\section{Desenvolvimento inicial e produtividade da cultura do milho no sistema de integração lavoura-pecuária}

\author{
Emerson Trogello ${ }^{*}$, Alcir José Modolo ${ }^{2}$, Ricardo Carnieletto ${ }^{3}$,Evandro Marcos Kolling 4 , \\ Marina Scarsi $i^{3}$, Maicon Sgarbossa ${ }^{3}$
}

\section{RESUMO}

A integração lavoura-pecuária pode ser definida como o sistema que integra duas atividades, visando a maximizar racionalmente o uso da terra e a minimizar os custos de produção. Objetivou-se, com este trabalho, avaliar os efeitos de diferentes alturas remanescentes de pastagem e de mecanismos sulcadores sobre o desenvolvimento inicial e a produtividade da cultura do milho semeado em sequência. Os tratamentos foram compostos pela combinação de quatro intensidades de pastagem $(0,05 ; 0,15 ; 0,30 \mathrm{~m}$ e sem pastejo) e de dois mecanismos sulcadores (haste e disco), utilizados na semeadura pós-pastejo. Após a semeadura, foram avaliados a profundidade de deposição das sementes, o índice de velocidade de emergência de plântulas, o estande final de plantas, a altura inicial e de inserção de espigas e o rendimento de grãos. As diferentes intensidades de pastagem influenciaram significativamente a profundidade de deposição de sementes, a altura inicial de plantas e de inserção da primeira espiga e a produtividade, sendo que a altura de pasto remanescente de $0,05 \mathrm{~m}$ apresentou os menores valores de profundidade de deposição de sementes, quando comparada com os demais níveis. Os diferentes mecanismos sulcadores influenciaram apenas a profundidade de deposição de sementes.

Palavras-chave: altura de pastagem, mecanismos sulcadores, semeadora.

\section{ABSTRACT}

\section{Early growth and yield of corn at the crop-livestock system}

Crop-livestock systems may be defined as the integration of two activities aiming to rationally maximize the land use and to decrease production costs. The objective of this study was to evaluate the effects of different heights of remaining pasture and seed drills on the yield of corn grown in sequence. The treatments consisted of combinations of four remaining pasture residue heights $(0,05 ; 0,15 ; 0,30 \mathrm{~m}$ and ungrazed) and two planter furrow openers on seed drills (shoe and disk), used for seeding after grazing. After corn sowing, the depth of seed deposition, the rate of seedling emergence, initial stand of plants, initial and final plant height and crop yield were evaluated. The different grass heights .significantly influenced the depth of seeding, the initial height and insertion of first cob and grain yield. Pasture height of 0,05 m corresponded to the lowest seed depth when compared with the other heights. The different furrow openers affected only the depth of seeding.

Key words: pasture height, planter furrow openers, drill seeder.

Recebido para publicação em 25/05/2010 e aprovado em 16/02/2012

'Engenheiro-Agrônomo. Pós-Graduando em Agronomia - PPGA, Bolsista CAPES, Universidade Tecnológica Federal do Paraná, Via do Conhecimento, Km 01, Caixa Postal 571, 85503-390, Pato Branco, Paraná, Brasil.etrogello@yahoo.com.br *Autor para correspondência

${ }^{2}$ Engenheiro Agrícola. Doutor, Coordenação de Agronomia (COAGR), Universidade Tecnológica Federal do Paraná, Via do Conhecimento, Km 01, Caixa Postal 571, 85503-390, Pato Branco, Paraná, Brasil. alcir@utfpr.edu.br

${ }^{3}$ Acadêmicos do Curso de Agronomia. Universidade Tecnológica Federal do Paraná, Via do Conhecimento, Km 01, Caixa Postal 571, 85503-390, Pato Branco, Paraná, Brasil. rcarnieletto@gmail.com; marinascarsi@hotmail.com; maicon_sgarbossa@hotmail.com

${ }^{4}$ Engenheiro Agrícola, Doutor. Coordenação de Engenharia Eletrônica, Universidade Tecnológica Federal do Paraná, Rua Cristo Rei, 19, 85902-490, Toledo, Paraná, Brasil. kolling@utfpr.edu.br 


\section{INTRODUÇÃO}

Uma prática que tem contribuído para a viabilização econômica das propriedades rurais e da semeadura direta é a integração lavoura-pecuária, que pode ser definida como um sistema que integra duas atividades com os objetivos de maximizar racionalmente o uso da terra, da infraestrutura e da mão de obra, diversificar e verticalizar a produção, minimizar custos, diluir os riscos e agregar valores aos produtos agropecuários, por meio dos recursos e benefícios que uma atividade proporciona à outra (Mello et al., 2004).

A cultura do milho destaca-se no contexto da integração lavoura-pecuária, pelas diversas aplicações deste cereal dentro da propriedade agrícola, quer seja na alimentação animal, na forma de grãos ou de forragem verde ou conservada (silagem), quer seja na alimentação humana ou na geração de receita, mediante a comercialização da produção excedente.

Para Terra Lopes et al. (2009), no sistema de integração lavoura-pecuária, o desafio é encontrar um nível de biomassa de forragem que promova elevado desempenho animal, ao mesmo tempo que permita alcançar alto rendimento de grãos na cultura subsequente. Para os autores, a manutenção de baixa biomassa residual, proporcionada por altas intensidades de pastejo, ocasionaria, do ponto de vista físico, degradação do solo, comprometendo o sistema semeadura direta. Segundo Albuquerque et al. (2001), uma das principais causas da degradação em áreas cultivadas é a compactação do solo causada pelo intenso tráfego de máquinas e implementos agrícolas e pelo pisoteio animal, em áreas de integração lavoura-pecuária.

Solos compactados caracterizam-se por apresentar diminuição do espaço poroso, com implicações sobre a movimentação de água e de gases no seu interior e na resistência que oferecem ao crescimento das raízes das plantas (Silva et al., 2000). Em geral, observa-se redução da taxa de infiltração de água no solo e diminuição na quantidade de água disponível às plantas (Tormena et al., 1998). Além disso, em períodos de chuvas intensas pode haver dificuldades nas trocas gasosas entre o solo e a atmosfera (Secco et al., 2004), resultando em decréscimo da produção de grãos (Beutler \& Centurion, 2004).

A alternativa utilizada para romper a camada superficial compactada nas regiões de solos argilosos tem sido o uso de sulcadores do tipo haste, que formam o sulco de semeadura com maiores profundidades, em comparação com os discos duplos, com consequente aumento da mobilização do solo, esforços de tração e exigência das potências dos motores (Araújo et al., 1999; Germino \& Benez, 2006).

Portella et al. (1997), ao avaliarem a influência dos sulcadores, tipo disco e tipo haste, sobre o índice de velocidade de emergência do milho, em semeadura direta, no sul do Brasil, não encontraram diferenças significativas entre os dois mecanismos. Koakoski et al. (2007), ao trabalharem com diferentes mecanismos sulcadores, encontraram maior profundidade de plantio, utilizando-se o mecanismo de abertura de solo tipo haste.

Com base no exposto, objetivou-se, com este trabalho, avaliar a influência de mecanismos sulcadores e de intensidades de pastejo dos animais sobre o desenvolvimento e produtividade da cultura do milho, no sistema de integração lavoura-pecuária, na região sudoeste do Paraná.

\section{MATERIAL E MÉTODOS}

O experimento foi desenvolvido em propriedade particular, localizada no município de Pato Branco - PR. A localização geográfica da área está definida pelas coordenadas 245' $30^{\prime \prime}$ Sul e 53³0'28" Oeste, sendo o clima subtropical úmido do tipo (Cfa), conforme classificação de Köppen, com altitude média de $730 \mathrm{~m}$ e precipitação média anual de $1.800 \mathrm{~mm}$. O solo predominante na área é classificado como Latossolo Vermelho aluminoférrico, com textura argilosa (77\% de argila, $20 \%$ de areia e $3 \%$ de silte).

Utilizou-se o esquema de parcelas subdivididas, em que as parcelas constituíram-se das quatro intensidades de pastejo $(0,05 ; 0,15 ; 0,30 \mathrm{~m}$ e sem pastejo) e, as subparcelas, dos dois diferentes mecanismos sulcadores (disco e haste), no delineamento em blocos ao acaso, com quatro repetições, totalizando 32 subparcelas.

Cada parcela tinha área de $160 \mathrm{~m}^{2}$, submetidas, anteriormente, ao cultivo de aveia preta para pastejo, a qual foi semeada em 7 de junho e submetida aos pastejos iniciais 80 dias após sua semeadura, quando detinha quantidade de matéria seca média de aproximadamente $5 \mathrm{t} \mathrm{ha}^{-1}$.

Para a realização do pastejo, utilizaram-se 7 vacas em lactação, com peso vivo médio de $478 \mathrm{~kg}$, as quais eram inseridas na área, no período diurno, e acomodadas em estalagens adequadas, antes da ordenha noturna, permanecendo na área não mais que 3 horas diárias, não se caracterizando assim, um sistema de pastejo contínuo.

Antes da alocação dos animais na área de pastejo, as parcelas "sem pastejo" foram cercadas, evitando-se a entrada de animais. Após sua inserção na área restante, os animais eram manejados até atingir a altura média de pastagem de 0,3 m, na área pastejada, e as parcelas que alcançavam essa altura eram cercadas. Esse procedimento foi seguido para as parcelas de $0,15 \mathrm{~m}$ e os animais foram retirados da área restante, ao se alcançar a altura média de 0,05 m. Uma vez que as intensidades de pastejos foram alcançadas, a partir do manejo de alturas de pastagens remanescentes, pôde-se utilizar uma carga animal constante, até atingir altura de $0,05 \mathrm{~m}$.

Após a realização dos diferentes níveis de pastejos, a área do experimento foi submetida à dessecação, utilizando-se o herbicida Glifosato Atanor, de amplo espectro de 
ação, na dosagem de 2,0 $\mathrm{L} \mathrm{ha}^{-1}$. No dia 10 de novembro de 2008, realizou-se a semeadura da cultura do milho, com o sistema de semeadura direta na palhada de aveia preta, a qual havia sido dessecada 15 dias antes. Utilizou-se o híbrido DKB 615, com população de 70.000 plantas ha $^{-1} \mathrm{e}$ a adubação, no momento da semeadura, constituiu-se de $300 \mathrm{~kg} \mathrm{ha}^{-1}$ da formulação 08-20-20 (NPK), seguindo análises de solo realizadas na área.

Para a realização da semeadura do milho em área póspastejada, utilizaram-se trator 4x2 TDA (Tração Dianteira Auxiliar), com potência máxima de 57,4 kW (78cv) a 2.400 rpm, e semeadora-adubadora de precisão, submetida à avaliação em uma única velocidade de deslocamento $(\mathrm{V}=$ $5,5 \mathrm{~km} \mathrm{~h}^{-1}$ ).

O controle da lagarta do cartucho (Spodoptera frugiperda) foi realizado aos sete e aos 50 dias após a semeadura, com a utilização do inseticida Permetrina, na dosagem de $0,1 \mathrm{~L} \mathrm{ha}^{-1}$ mais o inseticida Triflumuron, na dosagem de $0,05 \mathrm{~L} \mathrm{ha}^{-1}$, com volume de aplicação de $200 \mathrm{~L} \mathrm{ha}^{-1}$. Como adjuvante, utilizou-se óleo mineral, na dosagem de $0,8 \mathrm{~L} \mathrm{ha}^{-1}$. As plantas daninhas foram controladas com herbicida Atrazina + Simazina, sete dias após a semeadura do milho, na dose de 6,0 $\mathrm{L} \mathrm{ha}^{-1}$, conforme recomendação para as ervas daninhas encontradas.

A profundidade de semeadura foi determinada aos 20 dias após a semeadura, em todos os tratamentos experimentais, sendo retiradas 20 plantas por parcela. Com tesoura de poda, cortou-se a parte aérea do milho, rente ao solo e, com espátula, arrancou-se a parte enterrada no solo, medindo-se o comprimento do mesocótilo até a semente.

O índice de velocidade de emergência de plântulas (IVE) foi avaliado em um espaço de dez metros, na linha central de semeadura. A contagem das plântulas foi realizada diariamente, até que o número de plântulas emergidas se apresentasse constante. Cada planta foi considerada emergida a partir do instante em que rompeu o solo e pôde ser vista a olho nu, de algum ângulo qualquer e constante. A partir dessas contagens, expressou-se o IVE, utilizando-se a equação (1), adaptada de (Maguire, 1962).

$I V E=\frac{E_{1}}{N_{1}}+\frac{E_{2}}{N_{2}}+\ldots \frac{E_{n}}{N_{n}}$

Equação (1)

Em que:

IVE = índice de velocidade de emergência;

$\mathrm{E}_{1}, \mathrm{E}_{2}, \mathrm{E}_{\mathrm{n}}=$ número de plântulas emergidas, na primeira, segunda, ..., última contagem;

$\mathrm{N}_{1}, \mathrm{~N}_{2}, \mathrm{~N}_{\mathrm{n}}=$ número de dias após a semeadura à primeira, segunda, ..., última contagem.

Aos 30 dias após a semeadura, avaliou-se a altura inicial de 30 plantas por tratamento, utilizando-se régua gra- duada em centímetros, sendo as plantas mensuradas da base até o ápice. No final do ciclo da cultura do milho, avaliou-se a altura de inserção da primeira espiga, em 30 plantas por parcela, medindo-se da base até o nó de inserção da espiga. $\mathrm{O}$ estande final foi avaliado quanto ao número de plantas por tratamento, no momento de colheita do experimento e, a partir deste resultado, foi extrapolado este parâmetro para plantas por hectare.

Para as avaliações referentes aos componentes de rendimento da cultura (número de grãos por espiga e o peso de mil grãos), foram coletadas 30 espigas por tratamento. A produtividade de grãos foi determinada a partir da colheita manual de 50 plantas. O rendimento de grãos foi estimado por meio da extrapolação da produção colhida para um hectare, corrigindo-se a umidade para $13 \%$.

Os resultados obtidos foram tabulados e submetidos às análises de variância e a comparação de média foi feita pelo teste de Tukey, a 5\% de probabilidade, utilizando-se o aplicativo ASSISTAT.

\section{RESULTADOS E DISCUSSÃO}

\section{Profundidade de deposição de sementes, índice de velocidade de emergência, estande final $e$ altura inicial de plantas}

Na Tabela 1, são apresentados os valores médios da profundidade de deposição de sementes e observa-se que não houve interação significativa entre as intensidades de pastejo e os mecanismos sulcadores utilizados. Analisando-se individualmente os diferentes tratamentos, podese observar que, tanto os sulcadores, quanto as intensidade de pastejo influenciaram significativamente a profundidade de deposição de sementes, sendo que o sulcador tipo haste apresentou os maiores valores, enquanto a altura remanescente de pastagem de $0,05 \mathrm{~m}$ apresentou as menores profundidades de semeadura.

Segundo Silva et al. (2008), a profundidade de deposição das sementes pode afetar sua germinação, condicionada pela temperatura, teor de água, peculiaridades da semente, propriedades físicas e químicas do solo, clima e manejo da cultura, dentre outros fatores. Koakoski et al. (2007) e Weirich Neto et al. (2007), afirmam que, quanto maior a profundidade de deposição, maior o consumo de energia na emergência, além de prejuízos causados por baixas temperaturas e baixos níveis de oxigênio; já quanto menor a profundidade, maior a susceptibilidade da semente a estresses hídricos.

Esta maior profundidade encontrada para o sulcador tipo haste também foi observada por Araújo et al. (1999) e Mion \& Benez (2008), os quais alegam que a haste, por seu formato construtivo, tende a puxar o equipamento para baixo, acarretando maior profundidade de semeadura. 
Trabalhando com mecanismos sulcadores, dos tipos haste e disco duplo, na implantação da cultura do milho, Reis et al. (2003) encontraram maiores profundidades de deposição da semente para mecanismos do tipo disco duplo. Os autores atribuem este fato ao formato do disco, o qual confere maior estabilidade às paredes do sulco, fazendo que as sementes caiam em maior profundidade. Já Andreolla \& Gabriel Filho (2006), trabalhando com mecanismos sulcadores, em sistema de integração lavoura-pecuária, encontraram profundidades de sulco superiores quando do uso do sulcador tipo haste; quanto aos diferentes pastejos, não encontraram diferenças significativas.

Para o IVE e estande final de plantas, não se observaram diferenças entre as intensidades de pastejo e os mecanismos sulcadores utilizados e não houve interação entre os fatores.

Para Portella et al. (1997), o IVE é um dos melhores parâmetros para avaliar os conjuntos de mecanismos dosadores e de deposição de sementes de uma semeadora. Ao avaliarem seis semeadoras de soja e oito de milho, em condições de campo, verificaram que a emergência de plântulas foi $14 \%$ menor, quando as sementes foram depositadas com sulcadores de discos, provavelmente por terem sido colocadas mais superficialmente, em função do déficit hídrico, ocorrido durante a emergência. Embora as sementes tenham sido alocadas em menores profundidades, quando da utilização de disco, e nos pastejos até alturas remanescentes de 0,05 $\mathrm{m}$, os valores de IVE não diferiram entre os tratamentos no presente trabalho.
Camilo et al. (2004), em trabalho conduzido com dois sulcadores (disco e haste), em cultura do feijão, verificaram que o uso do mecanismo tipo haste proporcionou maior índice de velocidade de emergência.

Com relação à altura inicial de plantas, pôde-se observar que a altura remanescente de pastagem de $0,05 \mathrm{~m}$ apresentou os menores resultados. Esta menor altura de plantas devese também à menor profundidade de deposição de sementes, encontrada neste tratamento, expondo-as a condições adversas, retardando o desenvolvimento radicular e limitando, assim, o crescimento inicial das plantas. Quanto aos diferentes sulcadores utilizados, não apresentaram influência significativa na altura inicial de plantas.

\section{Altura de inserção de espigas, número de grãos por espiga, peso de mil grãos e produtividade média da cultura do milho}

Na Tabela 2, são apresentados os valores médios da altura de inserção da primeira espiga e observa-se que, dentre todos os fatores e interações estudados, apenas a intensidade de pastejo afetou de forma significativa, sendo os menores valores encontrados na altura remanescente de pastagem de $0,05 \mathrm{~m}$. Este resultado pode ser explicado, uma vez que esta intensidade de pastejo foi a que apresentou, também, a menor altura inicial de plantas (Tabela 1), tendo tendência a permanecer assim até o final do ciclo da cultura.

Verifica-se, na Tabela 2, que tanto o número de grãos por espiga, como o peso de mil grãos não foram influenciados, tanto pela altura remanescente de pastejo, como pelos diferentes sulcadores utilizados.

Tabela 1. Síntese da análise de variância e do teste de médias para as variáveis profundidade de deposição de sementes (cm), índice de velocidade de emergência (IVE), estande final (plantas ha ${ }^{-1}$ ) e altura inicial de plantas da cultura do milho $(\mathrm{cm})$

\begin{tabular}{|c|c|c|c|c|}
\hline \multirow{2}{*}{$\begin{array}{c}\text { Fator } \\
\begin{array}{c}\text { Altura de pastagem (A) } \\
(\mathrm{cm})\end{array}\end{array}$} & \multirow{2}{*}{$\begin{array}{l}\text { Profundidade de } \\
\text { deposição de } \\
\text { sementes }\end{array}$} & \multirow[b]{2}{*}{ IVE } & \multirow[b]{2}{*}{ Estande final } & \multirow{2}{*}{$\begin{array}{c}\text { Altura inicial de } \\
\text { plantas }\end{array}$} \\
\hline & & & & \\
\hline 5,0 & $2,87 \mathrm{~b}$ & 22,87 & $65.595,18$ & $87,27 \mathrm{~b}$ \\
\hline 15,0 & $3,54 \mathrm{ab}$ & 22,57 & $65.595,17$ & $108,37 \mathrm{a}$ \\
\hline 30,0 & $4,50 \mathrm{a}$ & 22,24 & $66.071,36$ & $104,22 \mathrm{a}$ \\
\hline Sem pastejo & $3,75 \mathrm{ab}$ & 21,81 & $65.238,03$ & 103,34 a \\
\hline Média & - & 22,38 & $65.624,94$ & - \\
\hline \multicolumn{5}{|l|}{ Sulcadores (S) } \\
\hline Haste & $3,67 \mathrm{a}$ & 22,47 & $65.892,79$ & 102,20 \\
\hline Disco & $3,43 \mathrm{~b}$ & 22,28 & $65.357,07$ & 99,40 \\
\hline Média & - & 22,38 & $65.624,94$ & 100,80 \\
\hline \multicolumn{5}{|l|}{ Teste F } \\
\hline A & $3,3500 *$ & $0,6080 \mathrm{~ns}$ & $0,3143 \mathrm{~ns}$ & $10,1565 * *$ \\
\hline S & $6,8627 *$ & $0,9350 \mathrm{~ns}$ & $0,8967 \mathrm{~ns}$ & $1,5097 \mathrm{~ns}$ \\
\hline $\mathrm{AxS}$ & $2,7647 \mathrm{~ns}$ & $1,9440 \mathrm{~ns}$ & $1,2214 \mathrm{~ns}$ & $1,4211 \mathrm{~ns}$ \\
\hline C.V. $(\%)$ & 7,34 & 2,43 & 2,43 & 6,39 \\
\hline
\end{tabular}

Médias seguidas por letras iguais na mesma coluna não diferem entre si pelo Teste de Tukey, a 5\% de probabilidade. ns - Não significativo. $*$ e $* *$ - Significativo a 5 e $1 \%$ de probabilidade, respectivamente pelo Teste $\mathrm{F}$. 
Tabela 2. Síntese da análise de variância e do teste de médias para as variáveis altura de inserção da primeira espiga (cm), número de grãos por espiga, peso de mil grãos $(\mathrm{g})$ e produtividade média da cultura do milho $\left(\mathrm{kg} \mathrm{ha}^{-1}\right)$

\begin{tabular}{|c|c|c|c|c|}
\hline $\begin{array}{c}\text { Fator } \\
\text { Altura de pastagem (A) } \\
(\mathrm{cm})\end{array}$ & $\begin{array}{l}\text { Altura de inserção } \\
\text { da primeira espiga }\end{array}$ & $\begin{array}{l}\text { Número de grãos por } \\
\text { espiga }\end{array}$ & $\begin{array}{l}\text { Peso de mil grãos } \\
\text { (g) }\end{array}$ & Produtividade média \\
\hline 5,0 & $87,78 \mathrm{~b}$ & 495,58 & 311,35 & $7.250,78 \mathrm{~b}$ \\
\hline 15,0 & $101,88 \mathrm{a}$ & 496,86 & 311,47 & $9.071,08 \mathrm{a}$ \\
\hline 30,0 & $98,92 \mathrm{a}$ & 496,83 & 311,17 & $8.694,34 \mathrm{a}$ \\
\hline Sem pastejo & $102,27 \mathrm{a}$ & 495,62 & 311,97 & $9.263,79 \mathrm{a}$ \\
\hline Média & - & 496,22 & 311,49 & - \\
\hline \multicolumn{5}{|l|}{ Sulcadores (S) } \\
\hline Haste & 96,22 & 496,37 & 311,68 & $8.729,28$ \\
\hline Disco & 99,22 & 496,08 & 311,30 & $8.410,72$ \\
\hline Média & 97,72 & 496,22 & 311,49 & $8.570,00$ \\
\hline \multicolumn{5}{|l|}{ Teste F } \\
\hline A & $6,7823 * *$ & $0,393 \mathrm{~ns}$ & $0,628 \mathrm{~ns}$ & $16,6052 * *$ \\
\hline S & $1,7037 \mathrm{~ns}$ & $0,069 \mathrm{~ns}$ & $0,866 \mathrm{~ns}$ & $1,1710 \mathrm{~ns}$ \\
\hline $\mathrm{AxS}$ & $1,3378 \mathrm{~ns}$ & $0,438 \mathrm{~ns}$ & $0,713 \mathrm{~ns}$ & $1,6479 \mathrm{~ns}$ \\
\hline C.V. $(\%)$ & 6,65 & 6,53 & 3,90 & 7,60 \\
\hline
\end{tabular}

Médias seguidas por letras iguais na mesma coluna não diferem entre si pelo Teste de Tukey, a 5\% de probabilidade. ns - Não significativo.

Com relação à produtividade da cultura do milho, pôde-se observar que, dentre todos os fatores e interações estudados, apenas as intensidades de pastejo afetaram de forma significativa a produtividade. $\mathrm{O}$ tratamento mais pastejado $(0,05 \mathrm{~m})$ resultou em menor produtividade, comparado com os demais tratamentos, por causa, principalmente, das condições desfavoráveis oferecidas à cultura no período inicial, proporcionando menor altura de plantas, o que pode resultar em menor interceptação de luz e menor taxa fotossintética, o que, consequentemente, culmina em menor acúmulo de biomassa e menor produtividade.

Assmann et al. (2003) afirmam que, para assegurar altas produtividades da cultura do milho, no sistema de integração lavoura-pecuária, tem-se a necessidade de acumular grandes quantidades de resíduos vegetais sobre o solo, no período pós-pastejo, afirmativa esta que foi confirmada neste trabalho, uma vez que a resteva de apenas $0,05 \mathrm{~m}$ não chega a propiciar uma quantidade de resíduo adequada ao desenvolvimento da cultura.

Nicoloso et al. (2006), verificaram que o aumento da intensidade de pastejo limitou o rendimento de grãos da cultura do milho, sendo que o tratamento mais pastejado reduziu o rendimento em até $1.290 \mathrm{~kg} \mathrm{ha}^{-1}$, em relação ao tratamento não pastejado, fato este relacionado com a maior compactação do solo em pastejos de maior intensidade. No presente trabalho, esta redução de rendimento foi de aproximadamente $2.013 \mathrm{~kg} \mathrm{ha}^{-1}$, entre o tratamento mais pastejado $(0,05 \mathrm{~m})$ e o não pastejado, o que se deve principalmente às condições iniciais inadequadas ao desenvolvimento das plantas, o que resultou em plantas de menor altura e vigor e, consequentemente, em menores capacidades competitivas e menores produtividades.

Com relação aos mecanismos sulcadores, observase que o uso da haste mostrou tendência à maior produtividade, provavelmente pela maior profundidade de trabalho da haste (Tabela 1). Mello \& Takahashi (2000), avaliando mecanismos sulcadores e rodas compactadoras de semeadoras-adubadoras para cultivo do milho em semeadura direta, também observaram a tendência de maior produtividade, quando se utiliza o sulcador do tipo haste.

\section{CONCLUSÕES}

Profundidade de deposição de sementes, altura inicial de plantas e altura de inserção da primeira espiga foram afetadas quando da permanência dos animais na área, até alturas de pastagem remanescentes de $0,05 \mathrm{~m}$.

Produtividades significativamente menores foram encontradas quando da permanência dos animais na área até altura de $0,05 \mathrm{~m}$.

Os mecanismos sulcadores afetaram de forma significativa apenas a profundidade de deposição de sementes, sendo que a maior profundidade foi obtida para o sulcador do tipo haste.

O índice de velocidade de emergência, o estande final de plantas, o número de grãos de espiga e o peso de mil grãos não foram influenciados pelas intensidades de pastejo nem pelos mecanismos sulcadores. 


\section{AGRADECIMENTO}

Os autores agradecem ao CNPq, Fundação Araucária, CAPES e a UTFPR, pela ajuda financeira e apoio de infraestrutura para o desenvolvimento do experimento.

\section{REFERÊNCIAS}

Albuquerque JA, Sangoi L \& Ender M (2001) Efeitos da integração lavoura-pecuária nas propriedades físicas do solo e características da cultura do milho. Revista Brasileira de Ciência do Solo, 25:717-723.

Andreolla VRM \& Gabriel Filho A (2006) Demanda de potencia de uma semeadora com dois tios de sulcadores em áreas compactadas pelo pisoteio de animais no sistema integração lavoura-pecuária. Revista Engenharia Agrícola, 26:768-776.

Araújo AG, Casão Júnior R, Ralisch R \& Siqueira R (1999) Mobilização de solo e emergência de plantas na semeadura direta de soja (Glycine $\max$ L.) e milho (Zea mays L.) em solos argilosos. Revista Engenharia Agrícola, 19:226-237.

Assmann TS, Ronzelli Júnior P, Moraes A, Assmann AL, Koehler HS \& Sandini I (2003) Rendimento de milho em área de integração lavoura-pecuária sob o sistema plantio direto, em presença e ausência de trevo branco, pastejo e nitrogênio. Revista Brasileira de Ciência do Solo, 27:675-683.

Beutler NA \& Centurion JF (2004) Matéria seca e altura das plantas de soja e arroz em função do grau de compactação e do teor de água de dois Latossolos. Revista Engenharia Agrícola, 24:142149

Camilo AJ, Fernandes HC, Modolo AJ \& Resende RC (2004) Influência de mecanismos rompedores e velocidades de trabalho no desempenho de uma semeadora-adubadora de plantio direto do feijão. Engenharia na Agricultura, 12:203-211.

Germino R \& Benez SH (2006) Ensaio comparativo em dois modelos de hastes sulcadoras para semeadoras-adubadoras de plantio direto. Revista Energia na Agricultura, 21:85-92.

Koakoski A, Souza CMA, Rafull LZL, Souza, LCF \& Reis EF (2007) Desempenho de semeadora-adubadora utilizando-se dois mecanismos rompedores e três pressões da roda compactadora Pesquisa Agropecuária Brasileira, 42:725-731.

Maguire JD (1962) Speed of germination-aid in selection and evaluation for seedling emergence and vigor. Crop Science, $2: 176-187$

Mello LMM, Yano ÉH, Narimatsu KCP, Takahashi CM \& Borghi E (2004) Integração agricultura-pecuária em plantio direto: produção de forragem e resíduo de palha após pastejo. Revista Engenharia Agrícola, 24:121-129.
Mello LMM \& Takahashi CM (2000) Avaliação de mecanismos rompedores e rodas compactadoras de semeadoras-adubadoras para a cultura do milho (Zea mays L.) em semeadura direta. In: $29^{\circ}$ Congresso Brasileiro de Engenharia Agrícola, Fortaleza. Anais, SBEA. p.1-4.

Mion RL \& Benez SH (2008) Esforços em ferramentas rompedoras de solo de semeadoras de plantio direto. Ciência e Agrotecnologia, 32:1594-1600

Nicoloso RS, Lanzanova ME \& Lovato T (2006) Manejo das pastagens de inverno e potencial produtivo de sistemas de integração lavoura-pecuária no Estado do Rio Grande do Sul. Ciência Rural, 36:1799-1805.

Portella JA, Sattler A \& Faganello A (1997) Desempenho de elementos rompedores de solo sobre o índice de emergência de soja e de milho em plantio direto do sul do Brasil. Engenharia na Agricultura, 5:209-217.

Reis EF, Cunha JPAN, Fernandes HC \& Rondón PP (2003) Influência de mecanismos rompedores de solo no desempenho de uma semeadora adubadora de plantio direto. Revista Ciências Técnicas Agropecuárias, 12:1-6.

Secco D, Reinert DJ, Reichert JM \& Da Ros CO (2004) Produtividade de soja e propriedades físicas de um latossolo submetido a sistemas de manejo e compactação. Revista Brasileira de Ciência do Solo, 28:797-804.

Silva RP, Cora JE, Filho AC.; Furlani, C.E.A \& Lopes, A (2008) Efeito da profundidade de semeadura e de rodas compactadoras submetidas a cargas verticais na temperatura e no teor de água do solo durante a germinação de sementes de milho. Ciência e Agrotecnologia, 32:929-937

Silva VR, Reinert DJ \& Reichert JM (2000) Resistência mecânica do solo à penetração influenciada pelo tráfego de uma colhedora em dois sistemas de manejo do solo. Ciência Rural, 30:795-801.

Terra Lopes ML, Carvalho PCF, Anghinoni I, Santos DT, Aguinaga AAQ, Flores JPC \& Moraes A (2009) Sistema de integração lavoura-pecuária: efeito do manejo da altura em pastagem de aveia preta e azevém anual sobre o rendimento da cultura da soja. Ciência Rural, 39:1499-1506.

Tormena CA, Rollof G \& Sá JCM (1998) Propriedades físicas do solo sob plantio direto influenciadas por Calagem, preparo inicial e tráfego. Revista Brasileira da Ciência do Solo, 22:301309 .

Weirich Neto PH, Schimandeiro A, Gimenez LM, Colet MJ \& Garbuio PW (2007) Profundidade de deposição de semente de milho na região dos campos gerais, Paraná. Revista Engenharia Agrícola, 27:782-786. 